\title{
Design of Multilevel Multicarrier H-Bridge Inverter fed Induction Motor Drive
}

\author{
$P$ Vinod Kumar
}

Department of EEE, CVR College of Engineering, Hyderabad, India

Email: onlyvinod56@gmail.com

\begin{abstract}
The design of H-Bridge Multilevel-multicarrier inverter fed variable frequency drive is discussed. A nine level inverter is proposed to drive a half hp induction motor. Simulation studies carried out on Single phase and three phase inverters using Simulink/MATLAB. The results are compared with a hardware module of single phase multi carrier inverter. The design aspects of three phase multicarrier inverter including the transformer design are presented in this paper.
\end{abstract}

Index Terms-Multilevel, H-bridge, SPWM, induction motor control, variable frequency drive, Total Harmonic Distortion (THD)

\section{INTRODUCTION}

Multilevel inverter is one of the areas in which a lot of research is taking place. Multilevel inverters are used in many applications like interface between photovoltaic systems and utility grids[1][2], motor drives [3], amplifiers used in broadcasting [4], and Power system applications like FACTS controllers [5]. Multilevel inverters can be classified into: 1. Cascaded H-Bridge 2. Diode clamped and 3. Flying capacitor type. Each type mentioned above can be designed in different topologies like basic stepped wave, Sinusoidal Pulse Width Modulation (SPWM) and Space Vector Pulse Width Modulation (SVPWM). The design of H-Bridge Multicarrier inverter using SPWM topology is presented using a simple control circuit. It is a s low cost option compared to multilevel inverters using advanced digital controllers like FPGA, DSP etc.,[6]. Another low cost alternative is the microcontroller based basic stepped wave inverter. But it has high THD value.

\section{CASCADED MULTI LEVEL INVERTER}

The H-Bridge inverter comprises of different $\mathrm{H}$ bridges connected in series as shown in figure 1. Each $\mathrm{H}-$ Bridge will be fed from an isolated DC power supply. The switching logic of the MOSFET/IGBTs in the bridge decides the output pattern of voltage and it's THD. A three level inverter output voltage swings over three levels of voltages $(+\mathrm{v} 0-\mathrm{v})$. The three voltage sources share the load current depending on the active period conducted by the switches of the bridge concerned. Two bridges required for designing a five level inverter. The general expression for the number of levels is $n=(2 b+1)$, where $b=$ number of bridges.

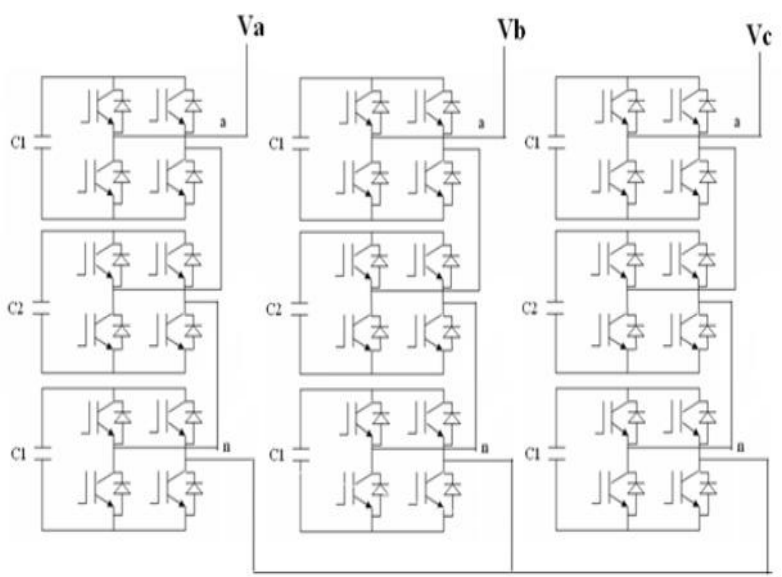

Figure.1 Three-phase 7-level cascaded multilevel inverter (Yconfiguration)

\section{SPWM TOPOLOGY}

One of the methods of describing voltage-source modulation is to illustrate the intersection of a modulating signal (duty cycle) with triangular waveforms.

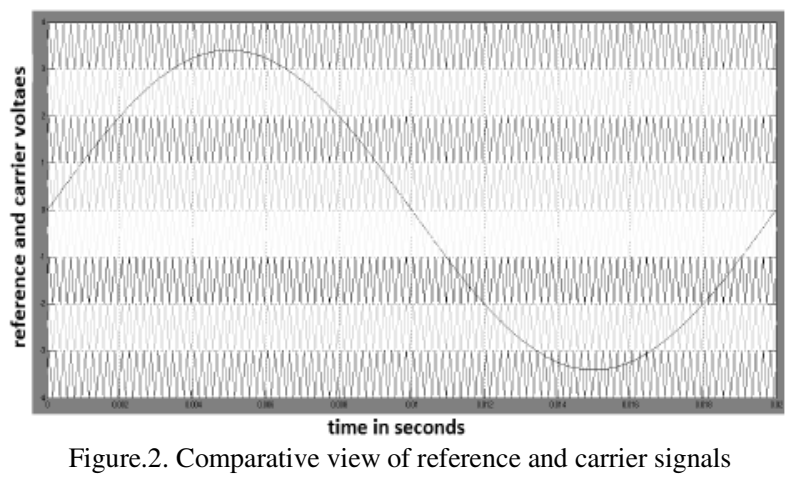

If modulation index (MI) is not an integer, there may exist sub harmonics at output voltage. If the normalized carrier frequency $\left(\mathrm{m}_{\mathrm{f}}\right)$ is not odd, DC component may exist and even harmonics are present at output voltage. $\mathrm{m}_{\mathrm{f}}$ should be a multiple of 3 for three-phase PWM inverter. The carrier-based modulation schemes for multilevel inverters can be generally classified into two categories: phase-shifted and level-shifted modulations. Both modulation schemes can be applied to the cascaded $\mathrm{H}$ bridge $(\mathrm{CHB})$ inverters. A level shifted modulation scheme with eight carrier signals are shown in figure 2 . 
An m-level CHB inverter using level-shifted multicarrier modulation scheme requires $(\mathrm{m}-1)$ triangular carriers, all having the same frequency and amplitude. The (m-1) triangular carriers are vertically disposed such that the bands they occupy are contiguous.

\section{EXPERIMENTAL RESULTS}

Based on the simulink software, simulations are performed to verify the performance of multilevel inverter. Figure 3 and figure 4 shows the simulation results of 9 level multicarrier inverter and figure 5 shows the THD result. The simulation parameters are set as follows: The DC input voltages to the H-bridges is $80 \mathrm{~V}$, the switching frequency is chosen to $1 \mathrm{kHz}$. The modulation index is set to 0.95 . The load resistance is $1 \mathrm{~K} \Omega$.

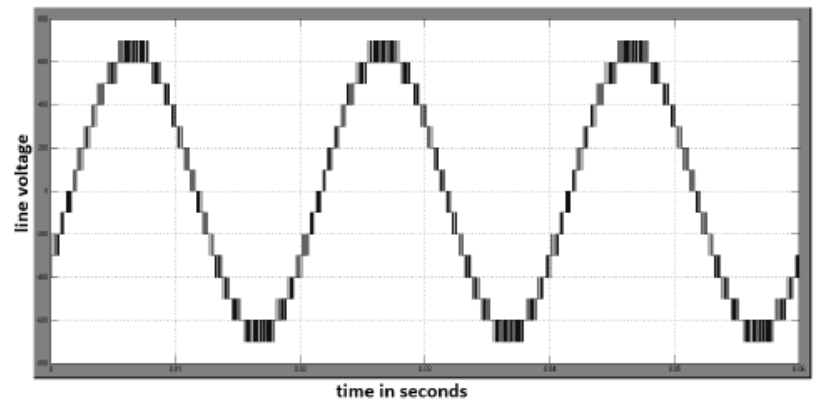

Figure 3. Line voltage of 9-level inverter

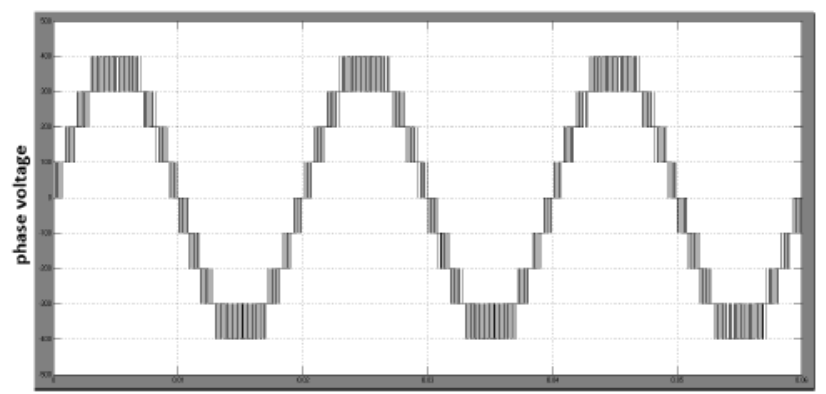

Figure 4. Phase voltage of 9-level inverter

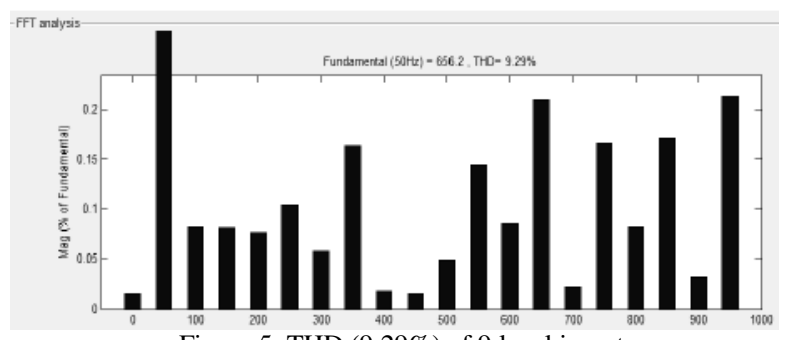

Figure 5. THD (9.29\%) of 9 level inverter

The simulation results for the modulation index 0.8 are shown in figures 6 and 7. The THD result is shown in figure 8 .

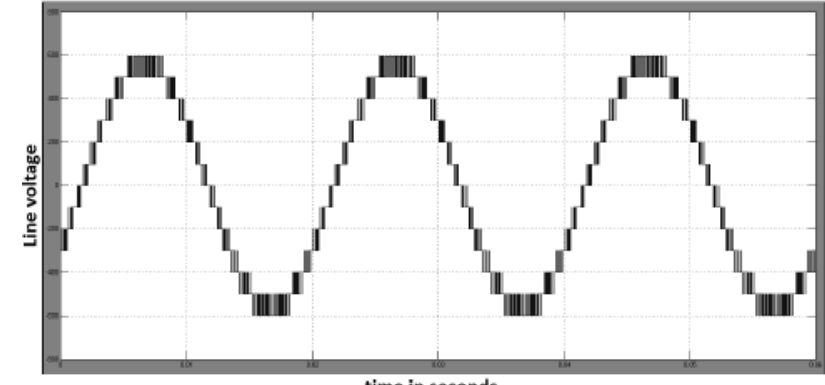

Figure 6. Line voltage at $\mathrm{MI}=0.8$

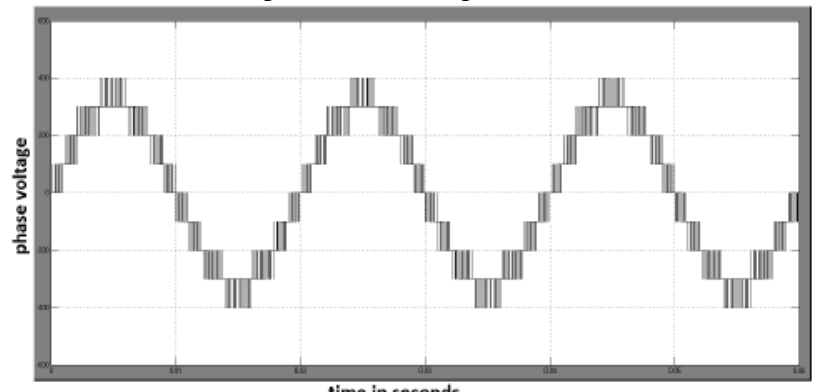

Figure 7. Phase voltage at $\mathrm{MI}=0.8$

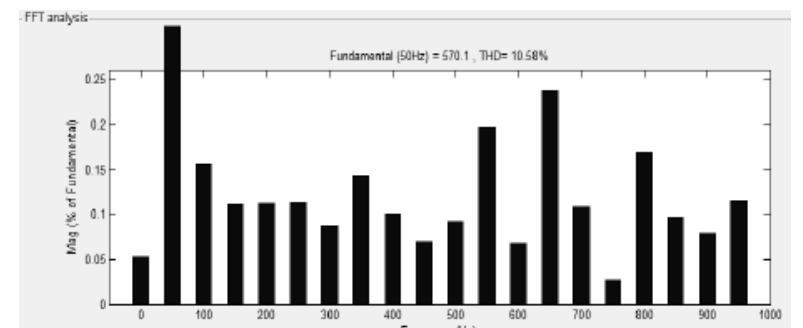

Figure 8. THD (10.58\%) of 9-level inverter at $\mathrm{MI}=0.8$

\section{HARDWARE DESCRIPTION}

Hardware design of this 9-level inverter involves two main parts. a) Control circuit, b) Power circuit.

The control circuit comprises of a reference sine wave which is stepped down from 230v AC line. A phase shifter circuit is used to produce three phase reference signals shown in figure 9. A triangular wave is generated from an analog IC (XR2206) and is clamped to eight desired levels using clampers (level shifters) shown in figure 10. The phase and level shifters are designed using 741 op-amps. 


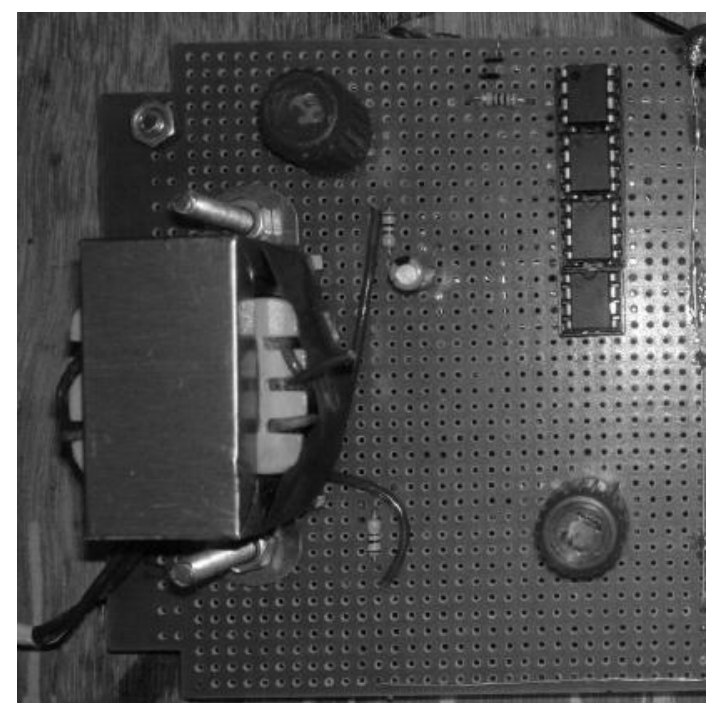

Figure 9. Op-amp 741 based Phase shifter circuit

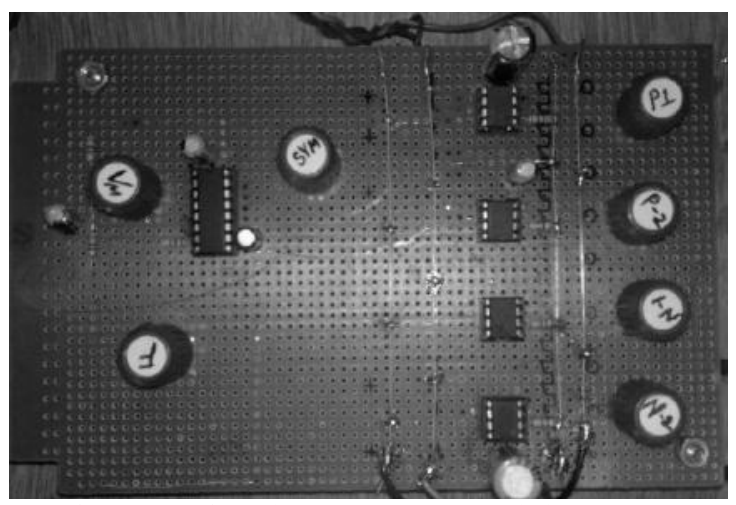

Figure 10. Triangular wave generator and clampers

Each phase of sine wave signal is compared with 12 comparators to generate triggering pulses for 4 switching states per phase. Each MOSFET requires an optocoupler and a separate DC supply is required to drive the optocoupler and hence the MOSFET. Each bridge requires three isolated dc power supplies (typically $12 \mathrm{v}$ ) and therefore total 36 sources are required for the complete three phase 9 - level inverter (four bridges / leg).

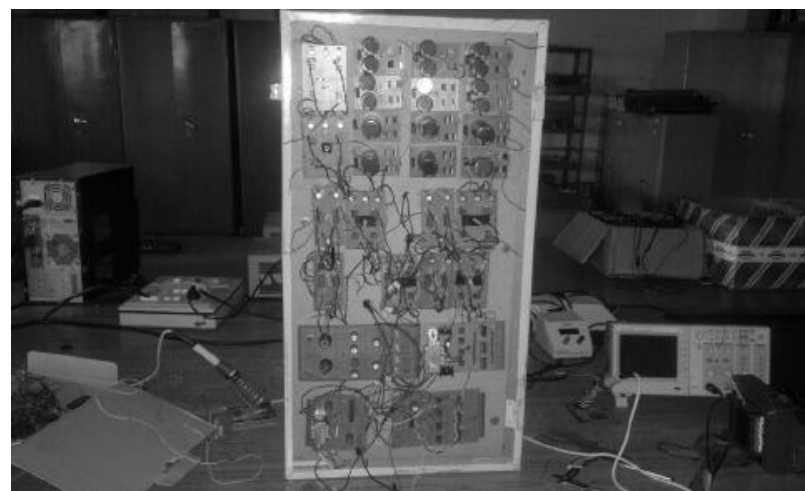

Figure 11. Hardware module of 9 - level CHB inverter

In addition to this, each bridge requires its own DC link power source. So, total 12 DC power sources required for the inverter. Each power supply rated $\mathrm{V}_{\text {peak }} /$ (no. of bridges in a leg $)=(230 * 1.414) / 4=81 \mathrm{v}$. The specifications of the transformer are given in the Table 1. The power and optocoupler transformers are shown in figure 12.

TABLE I

DESIGN SPECIFICATIONS OF TRANSFORMERS

\begin{tabular}{|l|l|l|l|l|l|l|l|}
\hline & Vp & Ip & Vs & Is & Np & Ns & $\begin{array}{l}\text { Sec. } \\
\text { coils }\end{array}$ \\
\hline $\begin{array}{l}\text { Power } \\
\text { transformer }\end{array}$ & $230 \mathrm{v}$ & $2.5 \mathrm{~A}$ & $81 \mathrm{v}$ & $0.6 \mathrm{~A}$ & 345 & 122 & 12 \\
\hline $\begin{array}{l}\text { Optocoupler } \\
\text { transformer }\end{array}$ & $230 \mathrm{v}$ & $100 \mathrm{~mA}$ & $12 \mathrm{v}$ & $50 \mathrm{~mA}$ & 432 & 23 & 36 \\
\hline
\end{tabular}

\section{Transformer winding calculations}

1. Power transformer (575VA)

$\mathrm{E}=4.44 * \mathrm{f} * \mathrm{~B} * \mathrm{~A} * \mathrm{~N}$

Therefore, turns/emf $=1 /(4.44 * \mathrm{f} * \mathrm{~B} * \mathrm{~A})$

For steel core, $\mathrm{B}=1 \sim 1.3$.

Let $\mathrm{B}=1.2$.

Cross section area of $575 \mathrm{VA}$ core is $5 \times 5 \mathrm{~cm}^{2}=$ $25 \mathrm{~cm}^{2}$.

Turns / emf $=1.5$ turn / volt.

For primary: $230 * 1.5=345$ turns, $19 \mathrm{AWG}$.

For secondary: $81 * 1.5=122$ turns, $25 \mathrm{AWG}$.

2. Optocoupler transformer (23VA)

3. Cross section area $=4 \times 5=20 \mathrm{~cm}^{2}$

Emf $/$ turn $=1.88$ turn/volt

For primary: 432 turns, 30AWG

For secondary: 23 turns, 30AWG

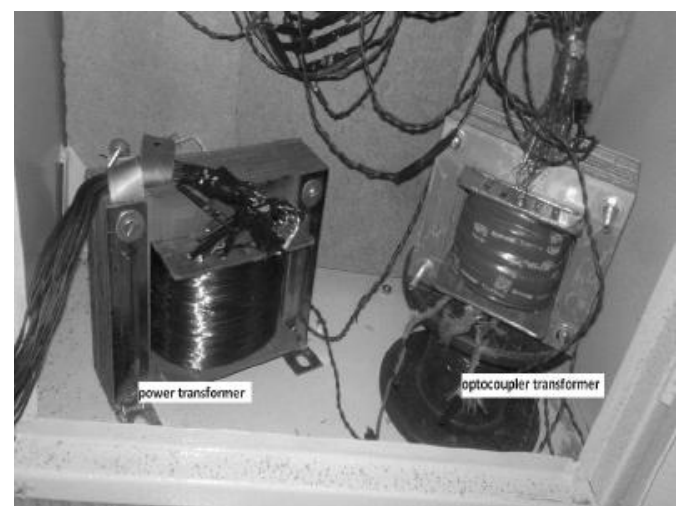

Figure 12. Power and Isolation Transformers 


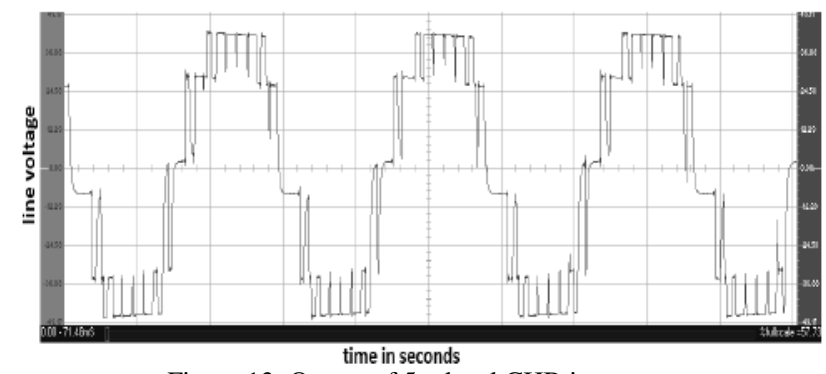

Figure 13. Output of 5 - level CHB inverter

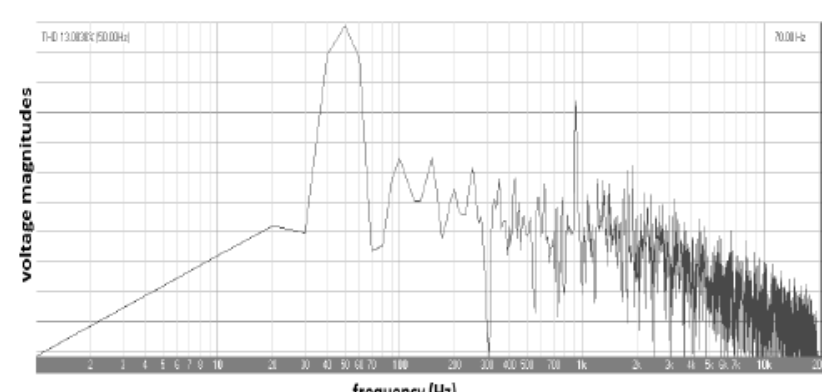

frequency $(\mathrm{Hz})$

Figure 14. THD of 5 - level CHB inverter

\section{CONCLUSIONS}

The H-bridge inverter is designed and fabricated with the proposed concept and is fed to a $1 / 2 \mathrm{hp}$ induction motor drive shown in figure 11 . The practical THD results are approximately equal to the simulation results and are shown in the figures 13 and 14. A detailed study on designing a transformer made the module simplified and compact in size. The experiment is conducted on low power motor but the power modules are designed for full load 7A motors. So, this set up is capable of driving medium level motors too.

\section{REFERENCES}

[1] P. Vinod Kumar, Ch. Santosh kumar and K. Ramesh Reddy, "Single phase cascaded multilevel inverter using multicarrier PWM technique", ARPN Journal of Engineering and Applied Science, VOL. 8, NO. 10, OCTOBER 2013

[2] V. Venus and K. Ramani "Implementation of closed loop system for diode clamped multilevel ineverter with standalone photovoltaic input," Global Journal of Engineering Electrical and Electronics Engineering vol. 13, issue 3, 2013.

[3] P. W. Hammond, "A New Approach to Enhance Power Quality for Medium Voltage AC Drives", IEEE Trans. On Ind. App., Vol. 33, No. 1, Jan./Feb. 1997, pp. 202-208.

[4] W. Schminke, "High Power Pulse Step Modulator For $500 \mathrm{KW}$ Short Wave and 600KW Medium Wave Transmitters", Brown BoveryReview, Vol. 72, No. 5, 1985, pp. 235-240.

[5] J. D. Ainsworth, M. Davies, P. J. Fitz, K. E. Owen and D. R. Trainer, "Static Var Compensator (STATCOM) Based on single phase chain circuit converters", IEE Proc. -Gener. Transm. Distrb., Vol. 145, No. 4, July 1998.

[6] Qiang Ni, Xiaoyun Feng, Wensheng Song, and Yongheng Liao,"Reduction of Torque Ripple of VSI-Fed PMSM Machine by Direct Torque Control Method "IEEE 7th International Power Electronics and Motion Control Conference - ECCE Asia June 2-5, 2012 